\title{
Molecular docking and pharmacokinetic studies of phytocompounds from Nigerian Medicinal Plants as promising inhibitory agents against SARS-CoV-2 methyltransferase (nsp16)
}

\author{
Tolulope Peter Saliu ${ }^{1,2^{*}}$ (D, Haruna I. Umar ${ }^{1}$, Olawale Johnson Ogunsile ${ }^{1}$, Micheal O. Okpara ${ }^{1}$,
} Noriyuki Yanaka ${ }^{2}$ and Olusola Olalekan Elekofehinti ${ }^{1}$

\begin{abstract}
Background: Since the index case was reported in China, COVID-19 has led to the death of at least 4 million people globally. Although there are some vaccine cocktails in circulation, the emergence of more virulent variants of SARS-CoV-2 may make the eradication of COVID-19 more difficult. Nsp16 is an S-adenosyl-L-Methionine-dependent methyltransferase that plays an important role in SARS-CoV-2 viral RNA cap formation-a crucial process that confers viral stability and prevents virus detection by cell innate immunity mechanisms. This unique property makes nsp 16 a promising molecular target for COVID-19 drug design. Thus, this study aimed to identify potent phytocompounds that can effectively inhibit SARS-CoV-2 nsp16. We performed in silico pharmacokinetic screening and molecular docking studies using 100 phytocompounds—isolated from fourteen Nigerian plants_as ligands and nsp16 (PDB: 6YZ1) as the target.
\end{abstract}

Results: We found that only 59 phytocompounds passed the drug-likeness analysis test. However, after the docking analysis, only six phytocompounds (oxopowelline, andrographolide, deacetylbowdensine, 11, 12-dimethyl sageone, sageone, and quercetin) isolated from four Nigerian plants (Crinum jagus, Andrographis paniculata, Sage plants (Salvia officinalis L.), and Anacardium occidentale) showed good binding affinity with nsp16 at its active site with docking score ranging from -7.9 to $-8.4 \mathrm{kcal} / \mathrm{mol}$.

Conclusions: Our findings suggest that the six phytocompounds could serve as therapeutic agents to prevent viral survival and replication in cells. However, further studies on the in vitro and in vivo inhibitory activities of these 6 hit phytocompounds against SARS-CoV-2 nsp16 are needed to confirm their efficacy and dose.

Keywords: COVID-19, SARS-CoV-2, Nsp16, Phytocompounds, Pharmacokinetics

\section{Background}

Severe acute respiratory syndrome coronavirus type 2 (SARS-CoV-2) is the most virulent human coronavirus $(\mathrm{HCoV})$ possessing the ability to affect the respiratory organ and cause multi-organ failures and other related

\footnotetext{
${ }^{*}$ Correspondence: tpsaliu@futa.edu.ng

${ }^{2}$ Graduate School of Integrated Sciences for Life, Hiroshima University,

4-4 Kagamiyama 1-chome, Higashi-Hiroshima 739-8528, Japan

Full list of author information is available at the end of the article
}

infections [1]. SARS-CoV-2 is the etiological agent for coronavirus disease 2019 (COVID-19). Since the index case of COVID-19 was reported in China, at least 187 million confirmed COVID-19 cases and over 4 million deaths have been recorded globally [2]. Lately, SAR$\mathrm{CoV}-2$ has undergone multiple mutations leading to the emergence of different variants which are more transmissible and virulent [3]. The deadlier variants of SARS$\mathrm{CoV}-2$ including the UK variant SARS-CoV-2 20I/501Y. 
V1, VOC 202012/01, or B.1.1.7; the South African strain SARS-CoV-2 20H/501Y.V2 or B.1.351; the Brazilian/Japanese variant SARS-CoV-2 P.1; and the other emerging variants are complicating the global burden of COVID$19[4,5]$.

Generally, coronaviruses have the largest genomes of all RNA viruses with approximately 29,800 bases that encode 4 structural proteins, 9 accessory proteins, and 16 non-structural proteins (nsp) numbered from nsp1-16 which are essential for the viral life cycle [6-8]. Although these proteins have been explored as therapeutic targets for COVID-19 drugs, most of the drugs are not without some side effects. Hence, there is an urgent need to take a parallel and multidirectional approach to counter the spread of SARS-CoV-2. Consequently, an extensive exploration of natural sources for therapeutic compounds which target SARS-CoV-2 protein(s) and have minimal or no side effects on humans become essential.

The distinguishing feature between eukaryotic and viral mRNAs is the presence of a $5^{\prime}$ cap in the former which confers stability on the eukaryotic mRNA. Thus, for SARS-CoV-2 to survive inside their host, they must develop a modification system to cap their RNAs at the $5^{\prime}$ end. The enzyme that mediates this capping in a methylation reaction is an S-adenosyl-L-Methionine-dependent methyltransferase which in the case of coronavirus is nsp16. Methylation enables the virus to mimic the host's mRNA structure thereby protecting the viral mRNA from degradation by the host's $5^{\prime}-3^{\prime}$ exoribonucleases [9]. As a result, the viral mRNA can escape recognition and targeting by the immune response thereby allowing efficient translation of the mRNA and subsequent production of virion particles. Notably, nsp16 is only active in the presence of its binding partner, nsp10, which is involved in the N-7 methylation of GTP nucleobase. These two proteins form an nsp16:nsp10 complex that is very crucial for the replication process of SARS-CoV-2 [10]. However, nsp16 has been recognized as a more promising and indispensable molecular target for therapeutic agents against COVID-19 [11]. More so, it has been shown that the substitution of a conserved region KDKE of nsp16 is sufficient to attenuate viral infection in vitro and in vivo [11, 12].

In this study, in silico virtual screening for potential drug candidates against coronavirus nsp16 was conducted with 100 compounds isolated from some Nigerian medicinal plants reported to possess antiviral properties.

\section{Methods}

\section{Protein target selection and preparation}

The 3-dimensional (3D) X-ray crystallographic structure of SARS-CoV-2 nsp10-nsp16 methyltransferase complex with Sinefungin (SFG) (PDB ID: 6YZ1) solved at $2.4 \AA$ resolution was retrieved from RCSB protein data bank (PDB) (https://www.rcsb.org/structure/6YZ1) (Fig. 1). The protein was prepared for docking by the following steps: (a) nsp10 protein was removed, (b) metal ions, water, and cofactors were removed, (c) bounded ligand SFG was removed, (d) polar hydrogen bond was added, and (e) finally, the nsp-16 protein was minimized using the relevant tools in Cresset Flare $\odot$ software, version 4.0 (https://www.cresset-group.com/flare/). The protein minimization was based on the General Amber Force Field (GAFF), with a gradient cutoff of $0.200 \mathrm{kcal} /$ $\mathrm{mol} / \mathrm{A}$, and iterations were set to 2000 iterations [13].

\section{Ligand selection and preparations}

A total of 100 phytocompounds isolated from fourteen Nigerian-based plants that have been previously reported to have antiviral activities were investigated. The plantsincluding Sage plants (Salvia officinalis L.), Borreria verticillate, Sida cordifolia, Licorice (Glycyrrhiza glabra), Crinum jagus, Andrographis paniculate, Phyllanthus amarus, Echinacea Purpurea, Anacardium occidentale, Khaya grandifoliola, Detarium microcarpum, Sterculia setigera, and Piliostigma thonningii-were selected for virtual screening and molecular docking study against SARS-CoV-2 nsp16 [14-20]. The 3D structures of most of the phytocompounds were obtained from the PubChem database (https://pubchem.ncbi.nlm.nih.gov/) in simple document format (SDF) while the structures of others were drawn using MarvinSketch $\odot$ (ver. 15.11.30). All the phytocompounds were optimized using Open Babel in Python Prescription (version 0.8) which converted the ligands to the most stable structures energetically using Merck molecular force field (MMFF94). The names of all the phytocompounds selected and their source plants are given in Table 1.

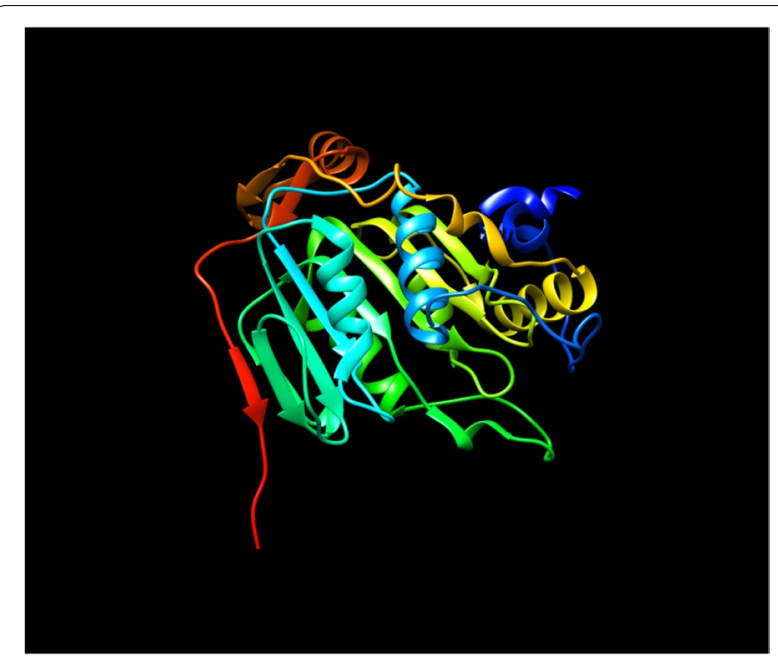

Fig. 1 3D structure of nsp16 free from nsp10 and Sinefungin 
Table 1 List of phytocompounds (numbered 1-100) obtained from 14 Nigerian medicinal plants having antiviral properties

\begin{tabular}{|c|c|c|}
\hline $\mathrm{S} / \mathrm{N}$ & $\begin{array}{l}\text { Name of medicinal plant } \\
\text { with antiviral properties }\end{array}$ & Major phytocompounds selected \\
\hline 1 & Sage plants (Salvia officinalis L.) & (1) Safficinollide, (2) Sageone, (3) 11,12-dimethyl sageone \\
\hline 2 & Borreria verticillate & (4) Verticillatine A, (5) Verticillatine B, (6) Scandoside methyl ester \\
\hline 3 & Sida cordifolia & $\begin{array}{l}\text { (7) B-phenethylamine, (8) Hypaphorine, (9)Vasicine, (10) Vasicinone, (11) Vasicinol, (12) Cryptolepine, (13) Malvalic } \\
\text { acid, (14) Sterculic Acid, (15) 5,7-dihydroxy-3-isoprenyl flavones, (16) 5-dihydroxy-3-isoprenyl flavones, (17) } \\
\text { 20-hydroxyecdysone, (18) 20-hydroxy-(25-acetyl)-ecdysone-3-O- } \beta \text {-D-glucopyranoside, (19) Sidasterone A,(20) } \\
\text { Sidasterone B,(21) S-(+)-N b-methyltryptophan methyl ester, (22) 5'-hydroxymethyl-1-(1,2,3,9-tetrahydro-pyrrolo } \\
\text { [2, 1-b] quinazoline-1-yl)-hepta-1-one) }\end{array}$ \\
\hline 4 & Licorice (Glycyrrhiza glabra) & (23) Licochalcone A, (24) Licochalcone E, (25) Glabridin, (26) Glycyrrhetinic acid, (27) Liquiritigerin \\
\hline 5 & Crinumjagus & $\begin{array}{l}\text { (28) Androlycorine, (29) Dihydrolycorine, (30) Vittatine (31) 8-O-demethylmaritidine, (32) Powelline, (33) Oxopow- } \\
\text { elline, (34) Buphanidrine, (35) Galanthamine, (36) Sanguinine, (37) Narwedine, (38) Deacetylbowdensine, (39) } \\
\text { Undulatine, (40) Galanthamine-N-Oxide, (41) Lycorine }\end{array}$ \\
\hline 6 & Andrographis paniculata & (42) Andrographolide, (43) Andrograpanin \\
\hline 7 & Phyllanthus amarus & $\begin{array}{l}\text { (44) Gallocatechin, (45) 4-O-Galloylquinic acid, (46) Corilagin, (47) Isocorilagin, (48) Phyllanthine, (49) Securinine, } \\
\text { (50) Isobubbialine, (51) Epibubbialine, ( 52)Nor securinine, (53) Oleanolic acid (54) Ursolic acid, (55) Linalool, (56) } \\
\text { Amarosterol A, (57) Amarosterol B, (58) Phyllanthenol, (59) Phyllantheol, (60) Lupeol, (61) Ellagic Acid, (62) Gallic } \\
\text { acid, (63) Phytol }\end{array}$ \\
\hline 8 & Echinacea purpurea & (64) Cichoric Acid, (65) Chlorogenic Acid, (66) Caffeic Acid, (67) Nitidarin diisovalerianate \\
\hline 9 & Anacardium occidentale & $\begin{array}{l}\text { (68) Stigmasterol, (69) (E)-caryophyllene, (70) Sitosterol 3-O- } \beta \text {-galactopyranoside, (71) Sitosterol, (72) Germacrene } \\
\text { D, (73) Quercetin 3-O-rhamnoside, (74) Quercetin, (75) Isoquercetrin, (76) Rutin }\end{array}$ \\
\hline 10 & Khaya grandifoliola & $\begin{array}{l}\text { (77) Deacetylkhayanolide E, (78) Khayanolide A, (79) 6-Phenyl,4-(1'oxyethylphenyl) hexane, (80) Benzene 1,1'-(oxy- } \\
\text { diethylidene) bis, (81) Carbamic acid, 4-methyl-1-phenyl)-1-phenyl }\end{array}$ \\
\hline 11 & Detarium microcarpum & $\begin{array}{l}\text { (82) 3,4-Epoxyclerodan-13E-en-15-oic acid, (83) } \\
\text { 5a,8a-(2-oxokolavenic acid), (84) Copalic acid, (85) 3,4-dihydroclerodan-13z-en-15-oic acid, (86) 3,4-dihydroxy- } \\
\text { clerodan-13E-en-15-oic acid, (87) Oxokolavemic acid }\end{array}$ \\
\hline 12 & Sterculia setigera & 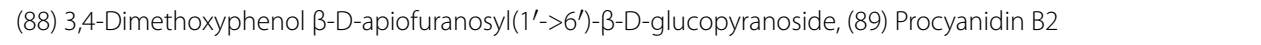 \\
\hline 13 & Piliostigma thonningii & 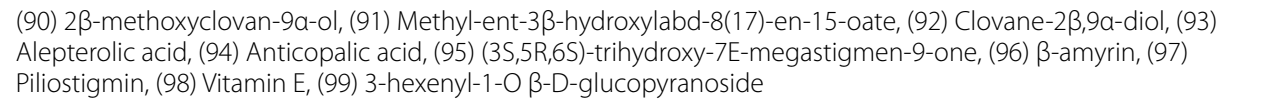 \\
\hline 14 & Detarium senegalense & (100) Anthocyanidin alkaloid \\
\hline
\end{tabular}

\section{Screening of compounds for drug-likeness}

The selected phytocompounds were screened for druglikeness and medicinal properties were predicted with the aid of SwissADME web tool (www.swissadme.ch/ index.php) [21]. The canonical SMILES of these compounds were uploaded on the server and run to predict their drug-likeness using several scoring schemes which included Lipinski's rule of five, Ghose's filter, Veber's rule, Egan's rule, and Muegge's rules [22-26].

\section{Molecular docking validation}

To substantiate the accuracy and reliability of the docking results, the docking protocol was validated according to our previous works [27, 28] which was based on the method by Warren et al. [29]. The purpose was to regenerate the binding pose and the molecular interaction of the co-crystalized ligand of the experimentally crystalized protein structure accurately. Thereupon, the native ligand Sinefungin (SFG) of the X-ray protein was detached from the protein and then prepared for docking in Cresset Flare $\odot$ software, version 4.0 (https://www.cresset-group.com/ flare/). The ligand was then re-docked back into the active site of nsp16 using AutoDock Vina in PyRx [30]. The docked complex was superimposed onto the X-ray resolved crystal of nsp16 bearing the co-crystalized ligand to compute the root mean square deviation (RMSD) value in PyMOL. The interaction analysis of both complexes was then evaluated using LigPlot $^{+}$ software [31].

\section{Molecular docking}

Molecular docking was accomplished via a flexible docking protocol [30]. Briefly, Python Prescription 0.8, a suite housing the AutoDock Vina module, was employed for the molecular docking study of 59 phytocompounds with SARS-CoV-2 nsp16. The specific target site for the receptor was set using the grid box with dimensions (21.6286 $\times 26.8772 \times 20.7369) \AA$, and the center was adjusted based on the active site of the enzyme which consists of the following amino acids: Tyr47, Asn43, His69, Asp99, Asn101, Asp114, Asp130, and Lys170. At the end of the docking experiment, phytocompounds with docking scores above the control Sinefungin (SFG) were subjected 

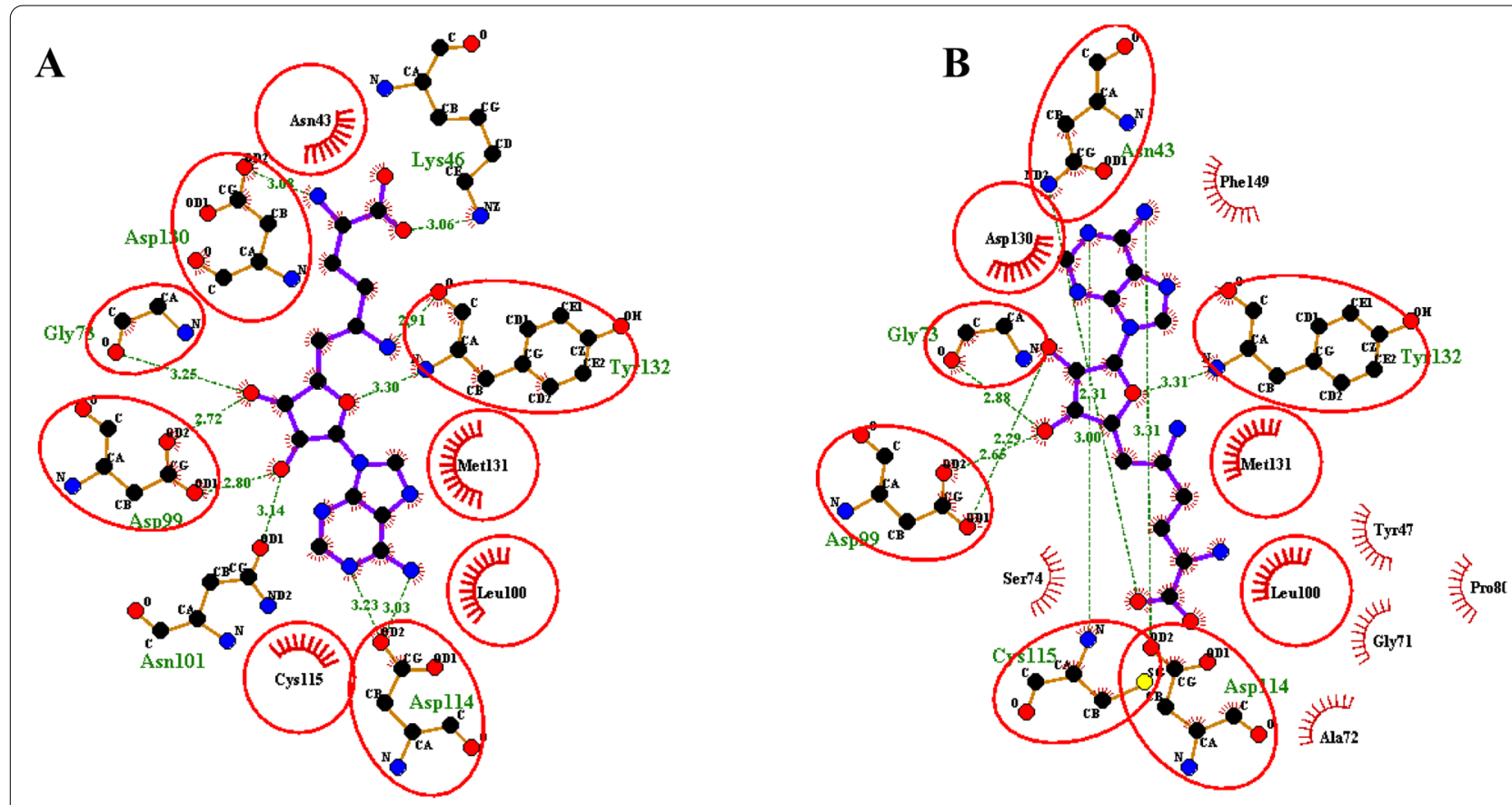

C

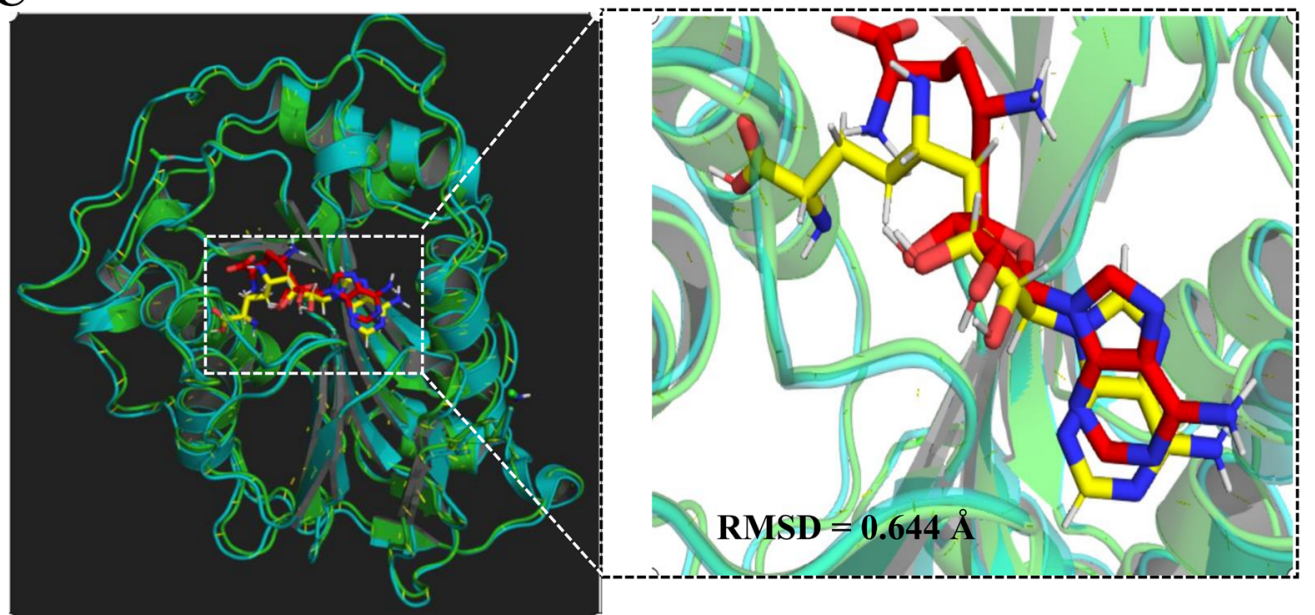

Fig. 2 2D molecular interaction analysis and superimposition of re-docked nsp16. A 2D molecular interaction of re-docked SGF with nsp16 active site. B The binding sites of SGF with nsp16 active site in co-crystalize complex. C Superimposition of the co-crystallized ligand (yellow) and the re-docked ligand (Red) $(\mathrm{RMSD}=0.644 \AA$ )

to molecular interaction analysis with the aid of PyMOL(C) Molecular Graphics (version 2.4, 2016, Shrodinger LLC) and Discovery Studio 2016๔.

\section{ADMET property prediction of active phytocompounds}

The ADMET (absorption, distribution, metabolism, excretion, and toxicity) properties of the hit phytocompounds obtained from our virtual screening were analyzed using admetSAR web server (http://lmmd. ecust.edu.cn/) [32]. The 3D structures of the top 6 phytocompounds were saved in canonical SMILES format and were uploaded on admetSAR web server. The predicted pharmacokinetic parameters which influence drug absorption include human intestinal absorption (HIA), blood-brain barrier permeation, and the likeliness of being P-glycoprotein substrate [33, 34]. The ability to inhibit different CYP450 enzymes or the likeliness of being a substrate to CYP450 enzymes $[35,36]$ are the significant properties predicted to influence phytochemical metabolism. Finally, toxicity predictions were performed 
Table 2 Binding affinity of compounds from antiviral plants when docked against nsp16

\begin{tabular}{|c|c|c|}
\hline $\mathrm{S} / \mathrm{N}$ & Compounds & $\begin{array}{l}\text { Binding } \\
\text { affinity (kcal/ } \\
\text { mol) }\end{array}$ \\
\hline 1. & Compound 1 & -5.9 \\
\hline 2. & 1-O-Caffeoylglycerol & -6.8 \\
\hline 3. & 1-O-pCoumaric acid & -6.1 \\
\hline 4. & compound 3 & -5.9 \\
\hline 5. & Compound 4 & -7.2 \\
\hline 6. & 5-dihydroxy-3-isopreyl flavones & -7.4 \\
\hline 7. & 5'-hydroxymethyl-1'-(1,2,3,9-tetrahydro & -6.7 \\
\hline 8. & compound 6 & -6.0 \\
\hline 9. & Compound 9 & -7.8 \\
\hline 10. & Compound 2 & -7.4 \\
\hline 11. & Compound 14 & -6.2 \\
\hline 12. & 3,4-dihydroxyclerodan-13E-en-15-0ic acid & -7.0 \\
\hline 13. & 5,7-dihydroxy-3-isoprenyl flavones & -7.7 \\
\hline 14. & 11,12-dimethyl sageone* & -8.1 \\
\hline 15. & Anthocyanidin alkaloid & -6.5 \\
\hline 16. & Benzene $1,1^{\prime}$-(oxydiethylidene) bis & -5.9 \\
\hline 17. & Caffeic Acid & -6.2 \\
\hline 18. & (4-methyl-1-phenyl)-1-phenyl Carbamic acid & -5.8 \\
\hline 19. & B-phenethylamine & -4.6 \\
\hline 20. & Vasicine & -6.1 \\
\hline 21. & Vasicinol & -6.4 \\
\hline 22. & Buphanidine & -7.3 \\
\hline 23. & Vasicinone & -6.7 \\
\hline 24. & Sterculic acid & -4.9 \\
\hline 25. & Vittatine & -7.2 \\
\hline 26. & Sanguinine & -7.0 \\
\hline 27. & Securinine & -6.7 \\
\hline 28. & Powelline & -7.3 \\
\hline 29. & Asperuloside & -7.4 \\
\hline 30. & Glabridin & -7.8 \\
\hline 31. & Phyllantine & -6.6 \\
\hline 32. & 8-O-demethylmaritidine & -6.7 \\
\hline 33. & Oxopowelline* & -7.9 \\
\hline 34. & Deacetylbowdensine* & -8.0 \\
\hline 35. & Andrlycorine & -7.2 \\
\hline 36. & Hypaphorine & -6.3 \\
\hline 37. & 3,4-Epoxyclerodan-13E-en-15-oic acid & -6.9 \\
\hline 38. & Andrograpanin & -7.1 \\
\hline 39. & 5alpha,8alpha-(2-oxokolavenic acid) & -6.5 \\
\hline 40. & Epibubbialine & -6.3 \\
\hline 41. & Copalic acid & -7.1 \\
\hline 42. & Dihydrolycorine & -7.8 \\
\hline 43. & Galanthamine & -6.5 \\
\hline 44. & Narwedine & -7.1 \\
\hline 45. & Undulatine & -7.2 \\
\hline 46. & Sageone* & -8.1 \\
\hline 47. & Scafficinolide & -6.8 \\
\hline
\end{tabular}

Table 2 (continued)

\begin{tabular}{lll}
\hline S/N & Compounds & $\begin{array}{l}\text { Binding } \\
\text { affinity (kcal/ } \\
\text { mol) }\end{array}$ \\
\hline 48. & Licochelcone A & -7.3 \\
49. & Licochelcone E & -7.0 \\
50. & Andrographolide* & -7.9 \\
51. & Isobubbialine & -6.0 \\
52. & Verticillatine A & -5.9 \\
53. & Ellagi acid & -7.8 \\
54. & Liquiritigerin & -7.8 \\
55. & Lycorine & -7.8 \\
56. & Oxokolavemic acid & -7.1 \\
57. & p-Coumaric acid & -5.3 \\
58. & Quercetin* & $-\mathbf{8 . 4}$ \\
59. & S-(+)-N b-methyltryptophan methyl ester & -6.1 \\
60. & SFG & $-\mathbf{7 . 9}$ \\
\hline
\end{tabular}

*Phytocompounds with the best binding affinity. "Reference compound

based on several computational models which included the Ames test for mutagenicity and carcinogenicity [32, 37].

\section{Results}

\section{Drug-likeness analysis of selected phytocompounds}

A drug-likeness analysis is an important segment of drug development that is used to identify the biological properties of drug candidates. We used SwissADME web tool to evaluate the drug-likeness properties of 100 phytocompounds isolated from fourteen Nigerian-based plants (Table 1). We found that 59 out of 100 phytocompounds (Supplimentary Table 1) tested satisfied all evaluated drug-likeness scoring schemes namely: Lipinski's rule of five, Ghose's filter, Veber's rule, Egan's rule, and Muegge's rules [22-26]. Thus, this filtered list of 59 phytocompounds was designated as druggable and was subsequently used for further analysis.

\section{Molecular docking validation}

To validate the docking procedure and to eliminate falsepositive results, two different methodologies were used namely re-docking and superimposition. After SFG (an inhibitor of nsp16) was removed and re-docked into the active site using AutoDock Vina in PyRx [30], we found that the inhibitor bound exactly to the active site with a binding energy of $-7.9 \mathrm{kcal} / \mathrm{mol}$. The re-docked complex was then found to interact with the same amino acid residues (Asn43, Gly73, Leu100, Asn101, Asp114, Cys115, Tyr132, Asp130, Met131, and Asp99) compared to the native co-crystallized complex (Fig. 2A, B) [11]. 
Table 3 Binding affinity and molecular interactions of the six hit compounds when docked against nsp16

\begin{tabular}{|c|c|c|c|c|c|}
\hline S/N. & Compounds & $\begin{array}{l}\text { Binding } \\
\text { affinity (kcal/ } \\
\text { mol) }\end{array}$ & $\begin{array}{l}\text { Hydrogen bond interactions } \\
\text { (distance) }\end{array}$ & Hydrophobic interactions & Electrostatic interactions \\
\hline 1 & Quercetin & -8.4 & $\begin{array}{l}\text { Asp130 (3.26), Gly73 (4.10) and } \\
\text { Leu100 (5.10) }\end{array}$ & $\begin{array}{l}\text { Met131, Phe149, Tyr132, Glu71, } \\
\text { Asp75, Ser74, Ala72, Ser98, Leu100, } \\
\text { Cys115, Asp114 and Asp133 }\end{array}$ & Asp99, $\pi-$ Anion \\
\hline 2 & Sageone & -8.1 & Leu100 (4.25) & $\begin{array}{l}\text { Met131, Phe149, Tyr132, Gly73, } \\
\text { Gly71, Asp75, Ser74, Ala72, Ser98, } \\
\text { Leu100, Cys115, Asp114 and } \\
\text { Asp133 }\end{array}$ & Asp99, $\pi-A n i o n$ \\
\hline 3 & 11, 12-Dimethylsageone & -8.1 & Met131 (4.72) and Tyr132 (5.72) & $\begin{array}{l}\text { Asn101, Ser74, Leu100, Asp114, } \\
\text { Asp133, Cys115, Phe149, Met131, } \\
\text { Gly71, Asp130, Asp99 and Asp75 }\end{array}$ & - \\
\hline 4 & Deacetylbowdensine & -8.0 & Gly73 (3.70) & $\begin{array}{l}\text { Ser74, Tyr132, Asp130, Phe149, } \\
\text { Leu100, Cys115, Ala116, Asp114, } \\
\text { Gly113, Met131, Gly71 and Asp99 }\end{array}$ & - \\
\hline 5 & Oxopowelline & -7.9 & $\begin{array}{l}\text { Phe149 (4.42), Leu100 (4.66), Cys115 } \\
\text { (3.72), Gly148 (4.11), Tyr132 (6.94) } \\
\text { and Asp99 (5.14) }\end{array}$ & $\begin{array}{l}\text { Phe149, Met131, Cys115, Asp114, } \\
\text { Gly113, Gly71 and Asp133 }\end{array}$ & - \\
\hline 6 & Andrographolide & -7.9 & $\begin{array}{l}\text { Gly71 (3.59), Asp99 (3.45), Asn43 } \\
\text { (4.44) and Asp130 (4.76) }\end{array}$ & $\begin{array}{l}\text { Cys46, Lys170, Tyr47, Asp75, Ser98, } \\
\text { Leu100, Met131, Asp133, Phe149, } \\
\text { Tyr132, Pro134 and Ser74 }\end{array}$ & - \\
\hline
\end{tabular}

Subsequently, using PyMOL, the re-docked nsp16:SFG complex was superimposed onto the native co-crystallized nsp16:SFG from PDB and the RMSD was calculated. Our result showed a low RMSD of $0.644 \AA$ (Fig. 2C). This partially suggests that the docking protocol was efficient and valid $[38,39]$.

\section{Molecular Docking}

The molecular docking of all 59 phytocompounds that passed the drug-likeness test was performed on SARSCoV-2 nsp16 (PDB ID: 6YZ1) using AutoDock Vina in PyRx [30]. We analyzed the active phytocompounds by binding free energies score and molecular interaction profile. Out of the 59 phytocompounds, only 6 (oxopowelline, andrographolide, deacetylbowdensine, 11, 12-dimethyl sageone, sageone, and quercetin) displayed the best binding affinity (ranging from -7.9 to -8.4 $\mathrm{kcal} / \mathrm{mol}$ ) and interactions (Tables 2 and 3, Fig. 3). The 2D structures of the 6 hit phytocompounds which displayed very efficient binding with nsp 16 are shown in Fig. 4 . The remaining 53 phytocompounds did not show efficient binding score; thus, they were not pursued further.

\section{ADMET properties prediction of active phytocompounds}

To reduce the high rate of attrition of candidates from the drug development pipeline, it is crucial to evaluate the ADMET properties of drug candidates. Therefore, the top 6 phytocompounds were subjected to ADMET properties prediction using the admetSAR web server [32]. The ADMET parameters predictions indicated that the 6 phytocompounds identified as potent nsp16 inhibitors abide by the pharmacokinetics rules and showed minimal cytotoxicity. As shown in Table 4, the prediction of HIA, the likeliness of being P-glycoprotein substrate, blood-brain barrier permeability, Ames mutagenesis, carcinogenicity, or aqueous solubility suggest that the 6 hit phytocompounds have suitable drug profile.

\section{Discussion}

The current treatment strategy that has been employed globally to combat COVID-19 involves the use of different vaccine cocktail which were developed from four major structural proteins (nucleocapsid protein, spike glycoprotein, membrane glycoprotein, and small envelope glycoprotein) of SARS-CoV-2. Most of these vaccines have demonstrated between 90 and 95\% efficacy against SARS-CoV-2 [40, 41]. However, with the emergence of several mutated variants of SARS-CoV-2, the efficacy of the current vaccine therapy may be reduced. Hence, this necessitates an urgent search for new therapeutic strategies to treat COVID-19. The non-structural protein, nsp16, is an important 2'-O-methyltransferase enzyme that is critical for converting viral mRNA cap-0 into cap-1 structure-an essential process that prevents virus detection by the host's cell innate immunity mechanisms [9, 39, 42, 43]. Targeted inhibition of nsp16, which plays a key role in viral RNA stability and life cycle, would be a valuable strategy for COVID-19 therapeutic intervention [11]. In the present study, we used in silico pharmacokinetic screening and molecular docking 


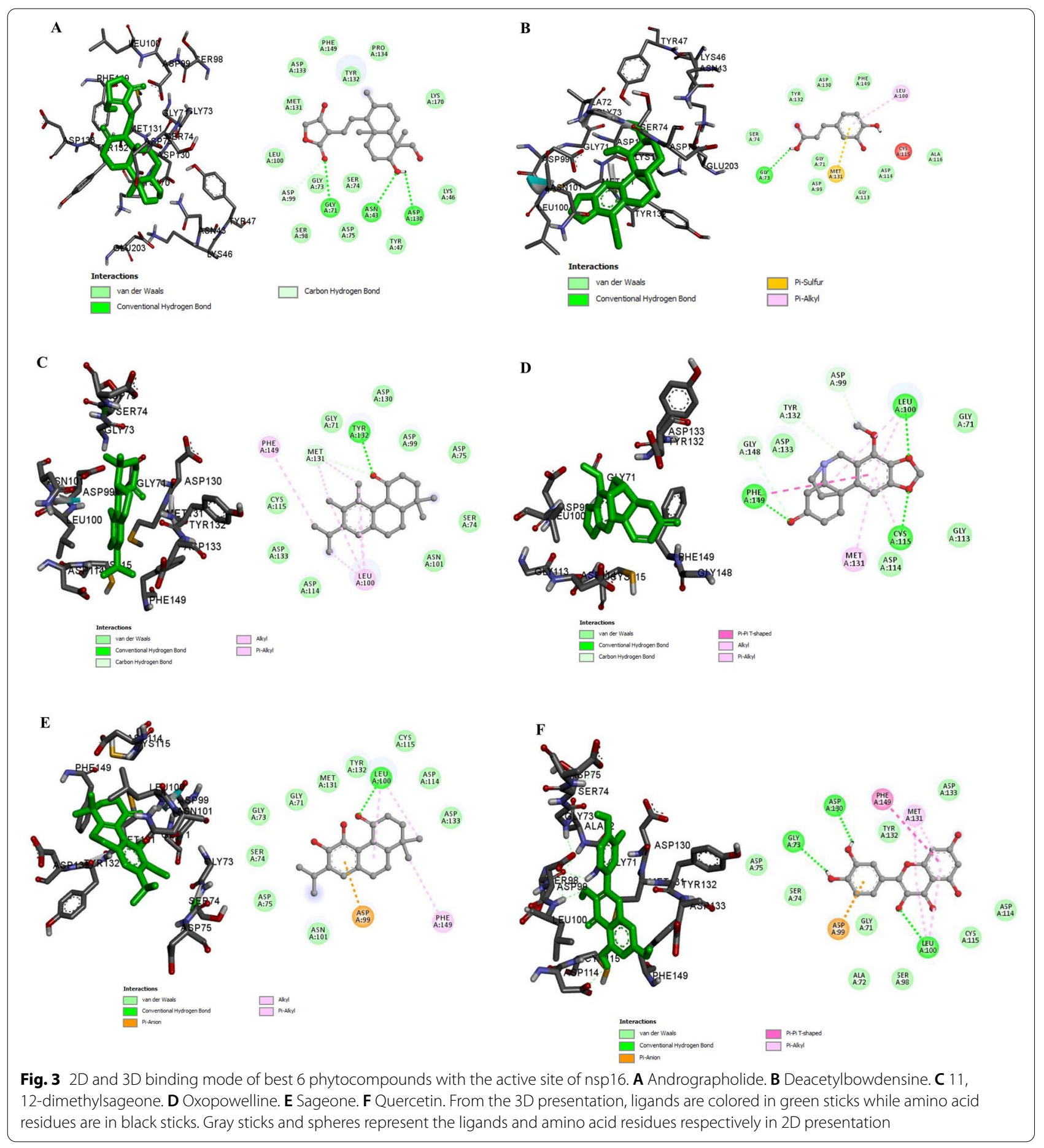

studies to discover 6 phytocompounds (oxopowelline, andrographolide, deacetylbowdensine, 11, 12-dimethyl sageone, sageone, and quercetin) isolated from four Nigerian plants (Crinum jagus, Andrographis paniculata, Sage plants (Salvia officinalis L.), and Anacardium occidentale) which showed potential to inhibit SARSCoV-2 nsp16.
Generally, phytocompounds isolated from numerous medicinal plants have been shown to be potential drug candidates for various viral and respiratory diseases [44]. For example, emodin (a phytocompound isolated from Rheum emodi) has been reported to significantly inhibit the $3 \mathrm{a}$ ion channel of SARS-CoV and $\mathrm{HCoV}-\mathrm{OC} 43$ as well as virus release from $\mathrm{HCoV}-\mathrm{OC} 4$ [45]. In a different 


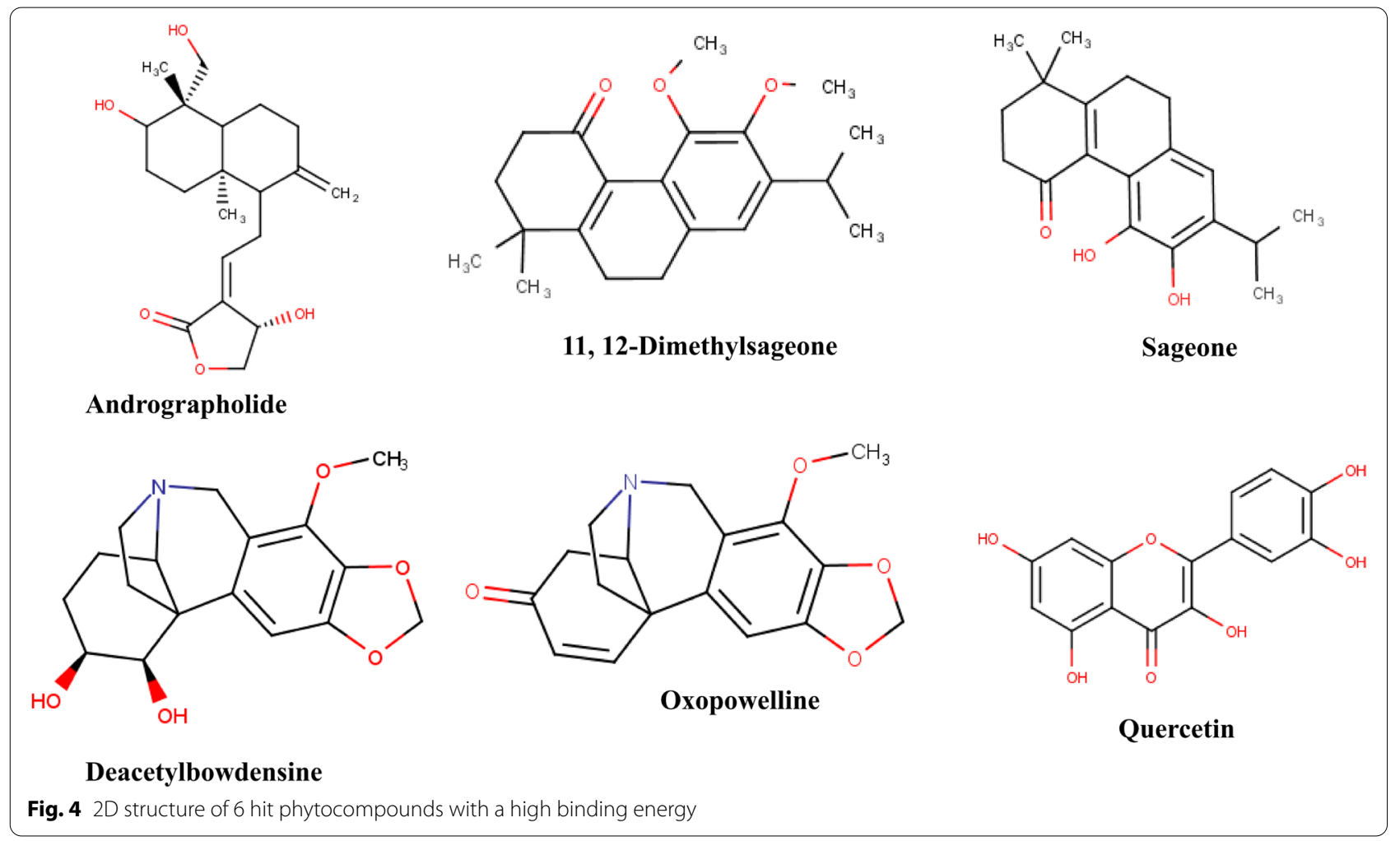

study, Ho et al. showed that emodin inhibited the direct binding of SARS-CoV S protein to ACE2 and S proteinpseudo-typed retrovirus [46]. Based on these reports, the search for phytocompounds from medicinal plant targeting key proteins/enzymes of SARS-CoV-2 could lead to the discovery of new therapeutic agents for treating COVID-19 disease. Thus, in this study, 100 phytocompounds from fourteen Nigerian medicinal plants, having antiviral properties, were subjected to drug-likeness analysis. This analysis ensured the removal of phytocompounds with poor pharmacokinetic parameters from the drug pipeline, thus saving time and cost [47]. Using SwissADME web tool, we found that 59 of the 100 phytocompounds screened are potentially druggable based on multiple scoring schemes.

Once we identified the phytocompounds that met the drug-likeness criteria, we used AutoDock Vina program in PyRx [30] to predict the possible binding affinity against SARS-CoV-2 nsp16. The docking score (- 7.9 $\mathrm{kcal} / \mathrm{mol}$ ) and binding pose of SFG were used as a reference $[11,48]$. By applying SFG as a reference compound, the molecular docking study revealed that out of the 59 phytocompounds screened, only six (oxopowelline, andrographolide, deacetylbowdensine, 11, 12-dimethyl sageone, sageone, and quercetin) showed efficient binding affinities with the active site of SARS-CoV-2 nsp16 (Tables 3 and 4). The top six phytocompounds identified were isolated from four (Crinum jagus, Andrographis paniculata, Sage plants (Salvia officinalis L.), Anacardium occidentale) out of the fourteen screened Nigerian medicinal plants with antiviral properties [14, 17-19, 49-52]. Oxopowelline and deacetylbowdensine with respective binding energies of $-7.9 \mathrm{kcal} / \mathrm{mol}$ and -8.0 $\mathrm{kcal} / \mathrm{mol}$ were isolated from Crinum jagus. Andrographolide with binging energy of $-7.9 \mathrm{kcal} / \mathrm{mol}$ was isolated from Andrographis paniculate. 11, 12-dimethyl sageon and sageon with binding energies of $-7.9 \mathrm{kcal} /$ $\mathrm{mol}$ and $-8.0 \mathrm{kcal} / \mathrm{mol}$ respectively were isolated from Sage plants (Salvia officinalis L.) while quercetin which possess the highest binding energy of $-8.4 \mathrm{kcal} / \mathrm{mol}$ was isolated from Anacardium occidentale. Although not so much investigation on the anti-SARS-CoV-2 activity of oxopowelline, deacetylbowdensine, 11, 12-dimethyl sageon, and sageon have been done, there are evidence that indicate that andrographolide and quercetin may be therapeutic agents against COVID-19. Following an in vitro study, Shi et al. reported that andrographolide and its fluorescent derivative (nitrobenzoxadiazole-conjugated andrographolide) inhibited the activities of both SARS-CoV and SARS-CoV-2 main protease $\left(\mathrm{M}^{\mathrm{pro}}\right)$. In a different study, Chen et al. showed that a quercetin derivative (quercetin-3-b-galactoside) inhibited the activity of SARS-CoV 3C-like protease $\left(3 \mathrm{CL}^{\mathrm{Pro}}\right)$ [53, 54]. Previous study has shown that among the amino acid residues 
Table 4 ADMET profiling of compounds with the best hit

\begin{tabular}{|c|c|c|c|c|c|c|c|}
\hline ADMET models & Oxopowelline & Deacetylbowdensine & Sageone & Andrographolide & $\begin{array}{l}\text { 11, } \\
\text { 12-Dimethyl } \\
\text { sageone }\end{array}$ & Quercetin & SFG \\
\hline Ames mutagenesis & - & - & - & - & - & + & - \\
\hline Acute oral toxicity (c) & III & III & III & III & III & $\|$ & III \\
\hline Androgen receptor binding & - & + & + & + & + & + & - \\
\hline Aromatase binding & - & - & + & + & - & + & - \\
\hline Avian toxicity & - & - & - & - & - & - & \\
\hline Blood-brain barrier & + & + & + & + & + & - & - \\
\hline BRCP inhibitor & - & - & - & - & - & + & \\
\hline Biodegradation & - & - & - & - & - & - & - \\
\hline BSEP inhibitor & + & + & - & + & + & - & \\
\hline Caco-2 & + & + & + & + & + & - & - \\
\hline Carcinogenicity & - & - & - & - & - & - & - \\
\hline CYP1A2 inhibition & - & - & + & - & - & + & - \\
\hline CYP2C19 inhibition & - & - & + & - & - & - & - \\
\hline CYP2C9 inhibition & - & - & - & - & - & - & - \\
\hline CYP2C9 substrate & - & - & - & - & - & - & - \\
\hline CYP2D6 inhibition & + & - & - & - & - & - & - \\
\hline CYP2D6 substrate & - & + & - & - & - & - & - \\
\hline CYP3A4 inhibition & + & + & - & - & - & + & - \\
\hline CYP3A4 substrate & + & + & + & + & + & + & - \\
\hline CYP inhibitory promiscuity & - & - & - & - & - & + & - \\
\hline Eye corrosion & - & - & - & - & - & - & - \\
\hline Eye irritation & - & - & - & - & - & + & - \\
\hline Estrogen receptor binding & + & + & + & + & + & + & - \\
\hline Fish aquatic toxicity & + & - & + & + & + & + & \\
\hline $\begin{array}{l}\text { Glucocorticoid receptor } \\
\text { binding }\end{array}$ & + & + & + & + & + & + & \\
\hline Honey bee toxicity & + & + & + & + & + & + & \\
\hline Hepatotoxicity & + & - & - & - & - & + & - \\
\hline $\begin{array}{l}\text { Human either-a-go-go inhibi- } \\
\text { tion }\end{array}$ & - & - & - & - & + & - & - \\
\hline Human intestinal absorption & + & + & + & + & + & + & - \\
\hline Human oral bioavailability & - & - & + & - & + & - & - \\
\hline MATE1 inhibitor & - & - & - & - & - & + & \\
\hline Acute oral toxicity & 2.36 & 2.73 & 1.5 & 2.79 & 1.36 & 2.56 & 1.19 \\
\hline OATP1B1 inhibitor & + & + & + & + & + & + & \\
\hline OATP1B3 inhibitor & + & + & + & + & + & + & \\
\hline OATP2B1 inhibitor & - & - & - & - & - & + & \\
\hline OCT1 inhibitor & + & - & + & - & + & - & \\
\hline OCT2 inhibitor & - & - & - & - & - & - & \\
\hline P-glycoprotein inhibitor & - & - & - & - & - & - & - \\
\hline P-glycoprotein substrate & - & - & - & - & - & - & + \\
\hline PPAR gamma & + & + & + & - & + & + & - \\
\hline Plasma protein binding & 0.72 & 0.89 & 1.17 & 0.54 & 1.17 & 1.17 & 7.61 \\
\hline Subcellular localization & Mitochondria & Lysosomes & Mitochondria & Mitochondria & Mitochondria & Mitochondria & Nucleus \\
\hline Tetrahymena pyriformis & 1.67 & 1.17 & 1.43 & 0.8 & 1.46 & 0.89 & 2.66 \\
\hline Thyroid receptor binding & - & + & + & + & + & + & \\
\hline UGT catalyzed & - & + & + & + & - & + & \\
\hline Water solubility & -2.55 & -2.22 & -4.84 & -2.85 & -4.72 & -3 & -0.73 \\
\hline
\end{tabular}


present in the active site of SARS-CoV-2 nsp16, six residues (Asp99, Asn101, Asn43, Asp130, and Lys170 and Asp114) are absolutely conserved [11]. Therefore, to prevent RNA methylation for coronaviruses, it is critical to prevent the interaction of any of these residues with the substrate (S-adenosylmethionine (SAM)). Interestingly, all the six phytocompounds can form hydrogen interaction with some of these residues.

Besides targeting SARS-CoV-2 nsp16, the 6 phytocompounds identified have been suggested as potential candidates with antibacterial, anti-inflammatory, antioxidant, antiviral activity, acetylcholinesterase (AChE), or butyrylcholinesterase (BChE) inhibitors [53-56]. Oxopowelline and deacetylbowdensine have recently been shown to be potential inhibitors of these two enzymes (BChE and AChE) [57]. Therefore, the inhibition of cholinesterase activities could be an additional strategy used by oxopowelline and deacetylbowdensine to prevent chronic cytokine storm associated with individuals with severe COVID-19. Furthermore, it is worth mentioning that the four plants containing the 6 identified phytocompounds have been reported to have other pharmacological effects that can be highly beneficial in the treatment of COVID19 symptoms such as cough, fever, muscle pain, chest pain, abdominal pain, and diarrhea [14, 17-19, 49-52]. In line with this, Andrographis paniculate and Anacardium occidentale have been reported to be traditionally used for the treatment of diarrhea and fever. Also, an in vivo study demonstrated that Salvia officinalis $L$. has analgesic and anti-inflammatory effects in mice and rats [58] suggesting the possibility of being used to alleviate the pain associated with COVID-19. A recent study has also demonstrated that Crinum jagus and Anacardium occidentale were some of the most popular plants used against cough, asthma, and other respiratory conditions in Nigeria [59], thus indicating that these plants may be highly effective in the management of cough which is associated with COVID-19 disease.

Finally, we examined the ADMET properties of the 6 phytocompounds to validate their pharmacokinetic potential against COVID-19 since a poor ADMET profile is sufficient to prevent therapeutic agents from getting clinical approval [60]. The ADMET profile result given in Table 4 indicated that none of the 6 compounds could be carcinogenic or inhibit p-glycoprotein. The HIA of all the 6 phytocompounds were favorable; however, only quercetin could be mutagenic and cross the blood-brain barrier. Interestingly, the benefits of quercetin was reported in some clinical trials and reviewed by Okamoto [61]. Similarly, clinical trial data on the use of andrographolide as treatment for acute and chronic throat and respiratory disease showed that it has no significant adverse effect in the patients [62]. Apart from oxopowelline and quercetin, all the other 4 phytocompounds showed no hepatotoxicity. The water solubility ranged between -4 and -2 , an indication that each of the 6 phytocompounds was either moderately soluble or highly soluble. Although our data indicated that quercetin could cross the blood-brain barrier, this does not nullify its potential as a drug candidate. The ability of quercetin to cross the blood-brain barrier is significant because it can help reduce brain cholinergic activity by inhibiting AChE and/or BChE activity [56]. Despite the in silico pharmacokinetic potential these 6 phytocompounds exhibit, their efficacies in both in vitro and in vivo pharmacokinetic settings need to be investigated.

\section{Conclusions}

Collectively, the promising results from the drug-likeness analysis, binding affinity, and ADMET profile of the 6 phytocompounds (oxopowelline, andrographolide, deacetylbowdensine, 11, 12-dimethyl sageone, sageone, and quercetin) isolated from four Nigerian plants reported in the present study reveal that either the phytocompounds or the four plants (Crinum jagus, Andrographis paniculata, Sage plants (Salvia officinalis L.), and Anacardium occidentale) could be explored as potential antiviral agents to inhibit SARS-CoV-2 nsp16. However, in vitro and in vivo studies would have to be carried out to validate our findings.

\section{Abbreviations \\ SARS-CoV 2: Severe acute respiratory syndrome coronavirus type 2; $\mathrm{HCOV}$ : Human coronavirus; Nsp 16: Non-structural proteins; ADMET: Absorption, dis- tribution, metabolism, excretion, and toxicity; BE: Binding energy; COVID-19: Coronavirus disease 19; AChE: Acetylcholinesterase; BChE: Butyrylcholinester- ase; SFG: Sinefungin.}

\section{Supplementary Information}

The online version contains supplementary material available at https://doi. org/10.1186/s43141-021-00273-5.

Additional file 1: Supplementary Table 1. Drug-likeness screening of phytocompounds from Nigerian based plants with antiviral properties.

\section{Acknowledgements}

Not applicable.

\section{Authors' contributions}

TPS and NY: Conceptualization and supervision. HIU, TPS, OOE: Investigation, methodology, and data interpretation. OJO, MOO: Biology related to SARSCoV-2 and validation. OJO, MOO, TPS: Writing - original draft preparation. NY, OOE: Writing - reviewing and editing. All authors read and approved the final manuscript.

\section{Funding}

Not applicable.

Availability of data and materials

We declare that all the data generated are included in this study. 


\section{Declarations}

Ethics approval and consent to participate

Not applicable.

\section{Consent for publication}

Not applicable.

\section{Competing interests}

The authors have no competing interests to declare.

\section{Author details}

${ }^{1}$ Computational and Molecular Biology Unit, Department of Biochemistry, Federal University of Technology, P.M.B 704, Akure, Ondo State, Nigeria. ${ }^{2}$ Graduate School of Integrated Sciences for Life, Hiroshima University, 4-4 Kagamiyama 1-chome, Higashi-Hiroshima 739-8528, Japan.

Received: 22 July 2021 Accepted: 26 October 2021

Published online: 09 November 2021

\section{References}

1. Ren LL, Wang YM, Wu ZQ, Xiang ZC, Guo L, Xu T et al (2020) Identification of a novel coronavirus causing severe pneumonia in human: a descriptive study. Chin Med 133(9):1015-1024. https://doi.org/10.1097/CM9.00000 00000000722

2. CRC., 2021. "The Johns Hopkins Coronavirus Resource Center." https:// coronavirus.jhu.edu/map.html. Accessed 19 June 2021.

3. Galloway SE, Paul P, MacCannell DR, Johansson MA, Brooks JT, MacNeil A et al (2021) Emergence of SARS-CoV-2 b. 1.1. 7 lineage-United States, December 29, 2020-January 12, 2021. Morb Mortal Wkly Rep 70(3):95-99

4. Greaney AJ, Loes AN, Crawford KH, Starr TN, Malone KD, Chu HY et al (2021) Comprehensive mapping of mutations in the SARS-CoV-2 receptor-binding domain that affect recognition by polyclonal human plasma antibodies. Cell Host Microbe 29(3):463-476. https://doi.org/10. 1016/j.chom.2021.02.003

5. Xie X, Zou J, Fontes-Garfias CR, Xia H, Swanson KA, Cutler M et al (2021) Neutralization of N501Y mutant SARS-CoV-2 by BNT162b2 vaccineelicited sera. BioRxiv:425740v1. https://doi.org/10.21203/rs.3.rs-143532/v1

6. Fehr AR, Stanley P (2015) Coronaviruses: an overview of their replication and pathogenesis. In: Coronaviruses: Methods and Protocols. Springer $p$, New York, pp 1-23

7. Snijder EJ, Decroly E, Ziebuhr J (2016) The nonstructural proteins directing coronavirus RNA synthesis and processing. Adv Virus Res 96:59-126. https://doi.org/10.1016/bs.aivir.2016.08.008

8. Wu A, Peng Y, Huang B, Ding X, Wang X, Niu P et al (2020) Genome composition and divergence of the novel coronavirus (2019-nCoV) originating in China. Cell Host Microbe 27(3):325-328. https://doi.org/10. 1016/j.chom.2020.02.001

9. Bradrick SS (2017) Causes and consequences of flavivirus RNA methylation. Front Microbiol 8:2374. https://doi.org/10.3389/fmicb.2017.02374

10. Chen Y, Su C, Ke M, Jin X, Xu L, Zhang Z, Wu A, Sun Y, Yang Z, Tien P, Ahola T (2011) Biochemical and structural insights into the mechanisms of SARS coronavirus RNA ribose 2'-O-methylation by nsp16/nsp10 protein complex. PLoS Pathog 7(10):e1002294 https://doi.org/10.1371/ journal.ppat.1002294

11. Krafcikova P, Silhan J, Nencka R, Boura E (2020) Structural analysis of the SARS-CoV-2 methyltransferase complex involved in RNA cap creation bound to sinefungin. Nat Commun 11(1):1-7 https://doi.org/10.1038/ s41467-020-17495-9

12. Decroly E, Imbert I, Coutard B, Bouvet M, Selisko B, Alvarez K et al (2008) Coronavirus nonstructural protein 16 is a cap-0 binding enzyme possessing (nucleoside-2' O)-methyltransferase activity. J Virol 82(16):8071-8084 https://doi.org/10.1128/jvi.00407-08

13. Stroganov OV, Novikov FN, Zeifman AA, Stroylov VS, Chilov GG (2011) TSAR, a new graph-theoretical approach to computational modeling of protein side-chain flexibility: modeling of ionization properties of proteins. Proteins 79(9):2693-2710 https://doi.org/10.1002/prot.23099
14. Aladesanmi AJ, Iwalewa EO, Adebajo AC, Akinkunmi EO, Taiwo BJ, Olorunmola FO et al (2007) Antimicrobial and antioxidant activities of some Nigerian medicinal plants. Afr J Tradit Complement Altern Med 4(2):173-184 https://doi.org/10.4314/ajtcam.v4i2.31206

15. Chan EW, Baba S, Chan HT, Kainuma M, Inoue T, Wong SK (2017) Ulam herbs: a review on the medicinal properties of Anacardium occidentale and Barringtonia racemosa. J Appl Pharm Sci 7(02):241-247 https://doi. org/10.7324/JAPS.2017.70235

16. Dluya T, Dahiru D (2018) Antibacterial activity of Piliostigma Thonningii methanol stem bark extract. Int J Res Pharm Biosci 5(1):15-20

17. Kudi AC, Myint SH (1999) Antiviral a ctivity of some Nigerian medicinal plant extracts. J Ethnopharmacol 68(1-3):289-294 https://doi.org/10. 1016/S0378-8741(99)00049-5

18. Ogbole OO, Akinleye TE, Segun PA, Faleye TC, Adeniji AJ (2018) In vitro antiviral activity of twenty-seven medicinal plant extracts from Southwest Nigeria against three serotypes of echoviruses. Virol J 15(1):1-8 https:// doi.org/10.1186/s12985-018-1022-7

19. Oladele JO, Ajayi El, Oyeleke OM, Oladele OT, Olowookere BD, Adeniyi BM et al (2020) A systematic review on COVID-19 pandemic with special emphasis on curative potentials of Nigeria based medicinal plants. Heliyon 9:e04897 https://doi.org/10.1016/j.heliyon.2020.e04897

20. Olugbuyiro JA (2009) Inhibitory activity of Detarium microcarpum extract against hepatitis C virus. Afr J Biomed Res 12(2):149-151

21. Daina A, Michielin O, Zoete V (2017) SwissADME: a free web tool to evaluate pharmacokinetics, drug-likeness and medicinal chemistry friendliness of small molecules. Sci Rep 7(1):1-3 https://doi.org/10.1038/srep42717

22. Egan WJ, Merz KM, Baldwin JJ (2000) Prediction of drug absorption using multivariate statistics. J Med Chem 43(21):3867-3877 https://doi.org/10. 1021/jm000292e

23. Ghose AK, Viswanadhan VN, Wendoloski JJ (1999) A knowledge-based approach in designing combinatorial or medicinal chemistry libraries for drug discovery. 1. A qualitative and quantitative characterization of known drug databases. J Comb Chem 1(1):55-68 https://doi.org/10. 1021/cc9800071

24. Lipinski CA, Lombardo F, Dominy BW, Feeney PJ (1997) Experimental and computational approaches to estimate solubility and permeability in drug discovery and development settings. Adv Drug Deliv Rev 23(13):3-25 https://doi.org/10.1016/S0169-409X(96)00423-1

25. Muegge I, Heald SL, Brittelli D (2001) Simple selection criteria for drug-like chemical matter. J Med Chem 44(12):1841-1846 https://doi.org/10.1021/ jm015507e

26. Veber DF, Johnson SR, Cheng HY, Smith BR, Ward KW, Kopple KD (2002) Molecular properties that influence the oral bioavailability of drug candidates. J Med Chem 45(12):2615-2623 https://doi.org/10.1021/ jm020017n

27. Umar HI, Josiah SS, Saliu TP, Jimoh TO, Ajayi A, Danjuma JB (2021) In-silico analysis of the inhibition of the SARS-CoV-2 main protease by some active compounds from selected African plants. J Taibah Univ Medical Sci 16(2):162-176 https://doi.org/10.1016/j.jtumed.2020.12.005

28. Umar HI, Siraj B, Ajayi A, Jimoh TO, Chukwuemeka PO (2021) Molecular docking studies of some selected gallic acid derivatives against five nonstructural proteins of novel coronavirus. J Genet Eng Biotechnol 19(1):1-4 https://doi.org/10.1186/s43141-021-00120-7

29. Warren GL, Andrews CW, Capelli AM, Clarke B, LaLonde J, Lambert MH et al (2006) A critical assessment of docking programs and scoring functions. J Med Chem 49(20):5912-5931 https://doi.org/10.1021/jm050362n

30. Trott O, Vina OA (2010) improving the speed and accuracy of docking with a new scoring function, efficient optimization and multithreading Oleg Public Access. J Comput Chem 31:455-461 https://doi.org/10.1002/ jcc. 21334

31. Laskowski RA, Swindells RB (2011) LigPlot+: multiple ligand-protein interaction diagrams for drug discovery. J Chem Inf Model 51:2778-2786 https://doi.org/10.1021/ci200227u

32. Cheng F, Weihua L, Yadi Z, Jie S, Zengrui W, Guixia L et al (2012) AdmetSAR: a comprehensive source and free tool for assessment of chemical ADMET properties. J Chem Inf Model 52:3099-3105 https://doi.org/10. 1021/ci300367a

33. Shen J, Cheng F, Xu Y, Li W, Tang Y (2010) Estimation of ADME properties with substructure pattern recognition. J Chem Inf Model 50:1034-1041 https://doi.org/10.1021/ci100104j 
34. Wang Z, Chen Y, Liang H, Bender A, Glen RC, Yan A (2011) P-glycoprotein substrate models using support vector machines based on a comprehensive data set. J Chem Inf Model 51(6):1447-1456 https://doi.org/10. $1021 /$ ci2001583

35. Cheng F, Yu Y, Shen J, Yang L, Li W, Liu G, Lee PW, Tang Y (2011) Classification of cytochrome P450 inhibitors and noninhibitors using combined classifiers. J Chem Inf Model 51(5):996-1011 https://doi.org/10.1021/ ci200028n

36. Cheng F, Yu Y, Zhou Y, Shen Z, Xiao W, Liu G et al (2011) Insights into molecular basis of cytochrome p450 inhibitory promiscuity of compounds. J Chem Inf Model 51(10):2482-2495 https://doi.org/10.1021/ ci200317s

37. Hansen K, Mika S, Schroeter T, Sutter A, Ter Laak A, Steger-Hartmann T et al (2009) Benchmark data set for in silico prediction of Ames mutagenicity. J Chem Inf Model 49(9):2077-2081 https://doi.org/10.1021/ci900 $161 \mathrm{~g}$

38. Elekofehinti OO, Ejelonu OC, Kamdem JP, Akinlosotu OB, Famuti A, Adebowale DD et al (2018) Discovery of potential visfatin activators using in silico docking and ADME predictions as therapy for type 2 diabetes. Beni Suef Univ J Basic Appl Sci 7(2):241-249 https://doi.org/10.1016/j.bjbas. 2018.02.007

39. Shivanika C, Kumar D, Ragunathan V, Tiwari P, Sumitha A (2020) Molecular docking, validation, dynamics simulations, and pharmacokinetic prediction of natural compounds against the SARS-CoV-2 main-protease. J Biomol Struct Dyn:1-27 https://doi.org/10.1080/07391102.2020.1815584

40. Knoll MD, Wonodi C (2021) Oxford-AstraZeneca COVID-19 vaccine efficacy. Lancet 397(10269):72-74

41. Polack FP, Thomas SJ, Kitchin N, Absalon J, Gurtman A, Lockhart S et al (2020) Safety and efficacy of the BNT162b2 mRNA Covid-19 vaccine. NEJM 383(27):2603-2615

42. Dong J, Wang NN, Yao ZJ, Zhang L, Cheng Y, Ouyang D et al (2018) ADMETlab: a platform for systematic ADMET evaluation based on a comprehensively collected ADMET database. J cheminformatics 10(1):1-1 https://doi.org/10.1186/s13321-018-0283-x

43. Ramanathan A, Robb GB, Chan SH (2016) mRNA capping: biological functions and applications. Nucleic Acids Res 44(16):7511-7526 https://doi. org/10.1093/nar/gkw551

44. Ben-Shabat S, Yarmolinsky L, Porat D, Dahan A (2020) Antiviral effect of phytochemicals from medicinal plants: applications and drug delivery strategies. Drug Deliv Transl Res 10(2):354-367 https://doi.org/10.1007/ s13346-019-00691-6

45. Schwarz S, Wang K, Yu W, Sun B, Schwarz W (2011) Emodin inhibits current through SARS-associated coronavirus 3a protein. Antiviral Res 90(1):64-69 https://doi.org/10.1016/j.antiviral.2011.02.008

46. Ho TY, Wu SL, Chen JC, Li CC, Hsiang CY (2007) Emodin blocks the SARS coronavirus spike protein and angiotensin-converting enzyme 2 interaction. Antiviral Res 74(2):92-101 https://doi.org/10.1016/j.antiviral.2006.04. 014

47. Agoni C, Olotu FA, Ramharack P, Soliman ME (2020) Druggability and drug-likeness concepts in drug design: are biomodelling and predictive tools having their say? J Mol model 26(6):1-1 https://doi.org/10.1007/ s00894-020-04385-6

48. Morales P, Curtis NL, Zárate SG, Bastida A, Bolanos-Garcia VM (2020) Interfering with mRNA methylation by the $2^{\prime}$ O-methyltransferase (NSP16) from SARS-CoV-2 to tackle the COVID-19 disease. Catalysts 10(9):1023 https://doi.org/10.3390/catal10091023

49. David AV, Arulmoli R, Parasuraman S (2016) Overviews of biological importance of quercetin: a bioactive flavonoid. Pharmacogn Rev 10(20):84-89 https://doi.org/10.4103/0973-7847.194044

50. Kumar G, Singh D, Tali JA, Dheer D, Shankar R (2020) Andrographolide: chemical modification and its effect on biological activities. Bioorg Chem 95:103511 https://doi.org/10.1016/j.bioorg.2019.103511
51. Massi A, Bortolini O, Ragno D, Bernardi T, Sacchetti G, Tacchini M et al (2017) Research progress in the modification of quercetin leading to anticancer agents. Molecules 22(8):1270 https://doi.org/10.3390/molec ules 22081270

52. Tada M, Okuno K, Chiba K, Ohnishi E, Yoshii T (1994) Antiviral diterpenes from Salvia officinalis. Phytochemistry 35(2):539-541 https://doi.org/10. 5005/jp/books/14225_30

53. Shi TH, Huang YL, Chen CC, Pi WC, Hsu YL, Lo LC et al (2020) Andrographolide and its fluorescent derivative inhibit the main proteases of 2019-nCoV and SARS-CoV through covalent linkage. Biochem Biophys Res Commun 533:467-473

54. Chen L, Li J, Luo C, Liu H, Xu W, Chen G et al (2006) Binding interaction of quercetin-3- $\beta$-galactoside and its synthetic derivatives with SARS-CoV 3CLpro: Structure-activity relationship studies reveal salient pharmacophore features. Bioorg Med Chem 14(24):8295-8306

55. Gomes IB, Porto ML, Santos MCL, Campagnaro BP, Pereira TM, Meyrelles SS et al (2014) Renoprotective, anti-oxidative and anti-apoptotic effects of oral low-dose quercetin in the C57BL/6J model of diabetic nephropathy. Lipids Health Dis 13(1):1-10

56. Ademosun AO, Oboh G, Bello F, Ayeni PO (2016) Antioxidative properties and effect of quercetin and its glycosylated form (Rutin) on acetylcholinesterase and butyrylcholinesterase activities. Evid Based Complement Alternat Med 21(4):NP11-NP17 https://doi.org/10.1177/2156587215 610032

57. Cortes N, Sierra K, Alzate F, Osorio EH, Osorio E (2018) Alkaloids of Amaryllidaceae as inhibitors of cholinesterases (AChEs and BChEs): An integrated bioguided study. Phytochem Anal 29(2):217-227 https://doi.org/10.1002/ pca.2736

58. Qnais EY, Abu-Dieyeh M, Abdulla FA, Abdalla SS (2010) The antinociceptive and anti-inflammatory effects of Salvia officinalis leaf aqueous and butanol extracts. Pharm Biol 48(10):1149-1156 https://doi.org/10.3109/ 13880200903530763

59. Lawal IO, Olufade II, Rafiu BO, Aremu AO (2020) Ethnobotanical survey of plants used for treating cough associated with respiratory conditions in Ede South local government area of Osun State, Nigeria. Plants 9(5):647 https://doi.org/10.3390/plants9050647

60. Guan L, Yang H, Cai Y, Sun L, Di P, Li W et al (2019) ADMET-score-a comprehensive scoring function for evaluation of chemical drug-likeness. Med Chem Comm 10(1):148-157

61. Okamoto T (2005) Safety of quercetin for clinical application. Int J Mol Med 16(2):275-278

62. Chang J, Zhang RM, Zhang Y, Chen ZB, Zhang ZM, Xu Q et al (2008) Andrographolide drop-pill in treatment of acute upper respiratory tract infection with external wind-heat syndrome: a multicenter and randomized controlled trial. Zhong Xi Yi Jie He Xue Bao 6(12):1238-1245

\section{Publisher's Note}

Springer Nature remains neutral with regard to jurisdictional claims in published maps and institutional affiliations.

\section{Submit your manuscript to a SpringerOpen ${ }^{\odot}$ journal and benefit from:}

- Convenient online submission

- Rigorous peer review

- Open access: articles freely available online

- High visibility within the field

- Retaining the copyright to your article

Submit your next manuscript at $\mathbf{s p r i n g e r o p e n . c o m ~}$ 